\title{
Performance evaluation of after-sales service partners in the power tools industry
}

\author{
Muhammad Wahid Malik Aljabar*, Sawarni Hasibuan \\ Master of Industrial Engineering, Universitas Mercu Buana, Meruya Selatan No.1 Street, Kembangan, Jakarta 11650, Indonesia
}

\begin{tabular}{l} 
ARTICLE INFORMATION \\
\hline Article history: \\
Received: October 30, 2021 \\
Revised: December 12, 2021 \\
Accepted: December 28, 2021 \\
\hline
\end{tabular}

Keywords:

After-sales service

Focus group discussion

Fault tree analysis

Performance

Power tools

\section{A B S T R A C T}

\begin{abstract}
After-sales service (ASS) is a product support activity provided to customers; after-sales service that focuses on quality can create a sustainable competitive advantage. This study aims to the ASS performance, analyze the causes of performance constraints that occur in ASS and recommendations for improving the performance of ASS conceptually. Service partner performance achievement can be assessed from four categories, i.e. very good, good, bad, and poor, based on the actual level of performance compared to performance targets. The sample of this research is 12 ASS partners in the electrical equipment industry in West Java and Jakarta. Factors causing failure were analyzed descriptively using the fault tree analysis (FTA) method, which involved experts in focus group discussions (FGD). Based on the evaluation, $25 \%$ of partners were rated good, $50 \%$ poor, and $25 \%$ very poor. Partner performance achievement is carried out on 22 performance indicators, of which 20 performance indicators have not achieved a good rating. These indicators relate to brand issues, warranty, training, parts control and stock management, pricing, and service systems, including service centers and service facilities. The proposed concept that becomes a recommendation for improving the performance of power tools ASS is improving the operating system and the selection of partners in the service center and service dealer categories with industrial customer segmentation.
\end{abstract}

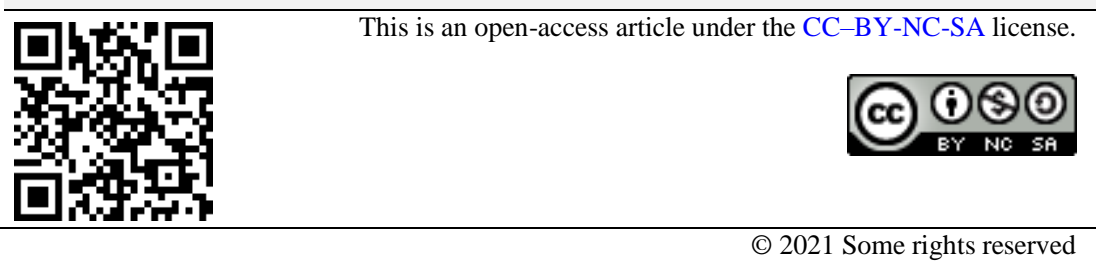

*Corresponding Author

Muhammad Wahid Malik Aljabar E-mail: mwahid41@gmail.com

\section{INTRODUCTION}

After-sales service (ASS) describes the product support activity services provided to customers [1]. After-sales is also a tool for product support, brand manifestation, customer relations, product support assurance, which generates acceptance through repair services, sales of parts and accessories [2]. ASS system as a tangible aspect where customers can interact with human, technical, physical resources of service providers and other customers [3]. Active support roles such as installation, technical usage advice, maintenance/repair, parts delivery, product upgrades to integrate services into core products [4]. ASS and warranty have extensive literature, providing more details on the mainstream such as warranty marketing aspects, warranty is treated as a competitive factor [5]. Servitization refers to a service-based strategy and its growing business implementation in manufacturing and other traditional product-based industries [6]. Most of the turnover for many manufacturers by the sale of new 
goods with their after-sales service becomes a mandatory addition to provide with new sales [7].

The focus on service quality is a key factor in creating a sustainable competitive advantage, with the main focus on rapid technological advances fundamentally changing the nature of service construction and business opportunities to become customer-oriented. [8]. Many producer companies are increasing their focus on ASS, and this is based on the fact that ASS is responsible for $20 \%$ of the company's turnover but can generate about $80 \%$ of profits for the company. To continue to be a profitable business area for the company, the process needs to be customer-oriented [9]. The influence of ASS quality factors on customer satisfaction in the car industry with the fuzzy Kano approach and identified 21 quality elements concerning SERVQUAL [10]. Performs qualitative and quantitative analysis of ASS with Quality Function Deployment (QFD) to identify competencies, product defects during the warranty period, repair time, duration of interaction with customers, employee attendance, and spare parts related to customer expectations [11]. Another study explored the influence of six factors identified as having a positive impact on service success, such as overall performance, innovation performance, customer satisfaction, and long-term partner retention of the service network in the context of servitization [12]. Companies are increasingly forming alliances to gain knowledge and seek a competitive advantage to access the required capabilities. The selection of strategic alliance partners is an important aspect of successful alliance development [13]. The operation of products and services within the supplier becomes the lifeline for the benefit of the supplier [14].

Performance in perspective is related to the activity of checking and measuring the object's ability to achieve the stated goals [15]. Regarding the customer's perspective on product serviceability, successfully identified four service-oriented dimensions, that is (1) dimensions of serviceability, (2) dimensions of serviceability guarantee, (3) serviceability responsiveness dimension has a positive effect on (4) customer satisfaction in ASS [16]. Performance partners who represent the best brands typically have processes focused on continuous improvement management, assurance, stock management, service scheduling, bonus offers, and customer service that emphasizes fault trees involving technical and commercial expertise.
Modern organizations build performance evaluation systems in their after-sales service units [17]. Performance appraisal enables organizations to be relevant organizational processes for service recovery [18]. To develop and implement a strategic approach, organizations need to understand how their customers perceive the key elements of service performance [19].

Performance measurement can be evaluated from two perspectives. The first that is widely used is the correlation between service levels and several financial performance indicators such as income and profits; second, which is used less frequently, is the achievement of a holistic set of goals, both financial and non-financial performance indicators. Service performance is also referred to as service success [6]. The key to a successful ASS system is to evaluate a comprehensive system of performance, service flexibility, company and personnel reliability, customer expectations about service, the impact of technological developments on customer satisfaction [20]. Related to several previous studies on ASS that became the reference in this study, most of the discussions were related to service quality in terms of customer expectations. Based on this background, this research focuses on evaluating service quality to achieve the performance of ASS partners. The purposes of this research are to (1) evaluate the actual achievement of after-sales service performance, (2) analyze the causes of performance constraints that occur in after-sales service, and (3) recommend a proposed after-sales service performance improvement conceptually.

Fault tree analysis (FTA), an established tool to study root cause problems in safety-critical systems, is introduced and employed rigorously and systematically in this research. FTA uses a deductive approach to conduct a top-down analysis. An undesired event is investigated through a chain of lower-level events using Boolean logic to identify its primary causes [21]. FTA is a causeand-effect analysis capable of tracking a system failure (one or more failures) at lower levels. FTA translates a physical system into a structured logic diagram, in which a certain sequence of basic events (causes) leads to a specified top event [22].

\section{RESEARCH METHODS}

This study uses a combination of quantitative and qualitative methods. The quantitative approach is used to measure the ASS performance, while the qualitative approach is used to determine 
the constraint factors that cause the ASS performance not to be achieved. The samples in this research are 12 ASS partners of the power tool industry operating in DKI Jakarta and West Java, while the determination of the number of samples used in this study is based on the Slovin formula equation (1) with $\alpha=5 \%$.

$n=\frac{N}{1+N(e)^{2}}$

Where n: sample size; N: population size, and E: percent allowance for inaccuracy due to tolerable or desirable sampling errors
In the study, there were two categories of ASS partners, including service center (SC); the focus of this ASS is on service and distribution of spare parts to customers and service dealers (SD). This ASS, in addition to providing service and distribution of spare parts to customers, also serves product distribution.

ASS partners in the SD category have two categories: service dealer (SD1), which distributes products to individual customers (traditional shop), and service dealer (SD2) serves the distribution of products to individual customers and has customers from companies or industries, and serves online transactions.

Table 1. Variables and indicators performance

\begin{tabular}{|c|c|c|}
\hline Variables & Indicators & Reference \\
\hline \multirow{4}{*}{$\begin{array}{c}\text { Competitive } \\
\text { Advantages } \\
\text { (CA) }\end{array}$} & Do you only serve one brand (Brand Loyalty) (CA1) & Ahmad \& Mohsin Butt [23] \\
\hline & Do you have an attached signboard identity (Brand & Ahmad \& Mohsin Butt [23] \\
\hline & Equity) (CA2) & \\
\hline & $\begin{array}{l}\text { Do technicians follow the training provided by the } \\
\text { center (CA3) }\end{array}$ & Murali et al. [24]; Brax et al. [6] \\
\hline \multirow{3}{*}{$\begin{array}{l}\text { Availability } \\
\text { (AV) }\end{array}$} & Is the stock of parts systematically monitored (AV1) & Murali et al. [24]; Borchardt et all. [2 \\
\hline & Are parts stock data reported monthly to the center (AV2) & Murali et al. [24]; Borchardt et all. [2 \\
\hline & $\begin{array}{l}\text { Do you run stock management and have a software } \\
\text { system (AV3) }\end{array}$ & Saccani et al. [4]; Borchardt et all. [2 \\
\hline \multirow{3}{*}{$\begin{array}{l}\text { Affordability } \\
\qquad(\mathrm{AF})\end{array}$} & $\begin{array}{l}\text { Does processing all incoming units use a software } \\
\text { system (Service Technology) (AF1) }\end{array}$ & Brax et al. [6] \\
\hline & $\begin{array}{l}\text { What is the total number of chargeable repair tools } \\
\text { repaired (AF2) }\end{array}$ & $\begin{array}{l}\text { Murali et al. [24]; Lightfoot \& } \\
\text { Gebauer [3] }\end{array}$ \\
\hline & $\begin{array}{l}\text { What is the total number of chargeable repair tools that } \\
\text { were not repaired (AF3) }\end{array}$ & $\begin{array}{l}\text { Murali et al. [24]; Lightfoot \& } \\
\text { Gebauer [3] }\end{array}$ \\
\hline \multirow{4}{*}{$\begin{array}{l}\text { Accessibility } \\
\qquad(\mathrm{AC})\end{array}$} & Do provide regular tool pick-up service (AC1) & Pistoni \& Songini [25] \\
\hline & $\begin{array}{l}\text { How many tools are the results of the pick-up service } \\
\text { (AC2) }\end{array}$ & Pistoni \& Songini [25] \\
\hline & $\begin{array}{l}\text { Do you have a special phone number that can be } \\
\text { contacted at any time (AC3) }\end{array}$ & Murali et al. [24] \\
\hline & $\begin{array}{l}\text { Does it have a convenient location (easy to access, } \\
\text { parking is available, safe) (AC4) }\end{array}$ & Pistoni \& Songini [25] \\
\hline \multirow{4}{*}{ Quality (Q) } & $\begin{array}{l}\text { Are the workshop work tools available complete, and } \\
\text { always in a ready-to-use condition (Q1) }\end{array}$ & Ahmad et al. [26] \\
\hline & Do operations follow central procedures $(\mathrm{Q} 2)$ & Lightfoot \& Gebauer [3] \\
\hline & $\begin{array}{l}\text { Is the warranty process running according to the } \\
\text { provisions from the center }(\mathrm{Q} 3)\end{array}$ & Borchardt et al. [6] \\
\hline & $\begin{array}{l}\text { Are used parts stored according to the provisions of the } \\
\text { center (Q4) }\end{array}$ & Pistoni \& Songini [25] \\
\hline \multirow{4}{*}{$\begin{array}{l}\text { Performance } \\
\text { \& User } \\
\text { Satisfaction } \\
\text { (PU) }\end{array}$} & $\begin{array}{l}\text { Do you have a software system that monitors the status } \\
\text { and duration of repairs (Service Technology) (PU1) }\end{array}$ & Brax et al. [6] \\
\hline & How many tools are completed in 24 hours (PU2) & $\begin{array}{l}\text { Murali et al. [24]; Lightfoot \& } \\
\text { Gebauer [3] }\end{array}$ \\
\hline & What is the total number of warranty tools repaired (PU3) & $\begin{array}{l}\text { Murali et al. [24]; Lightfoot \& } \\
\text { Gebauer [3] }\end{array}$ \\
\hline & Do regularly collect input from users (PU4) & Brax et al. [6] \\
\hline
\end{tabular}


The ASS performance of the power tool industry is measured using six variables, namely competitive advantages (CA), availability (AV), affordability (AF), accessibility (AC), quality (Q), and performance \& user satisfaction (PU). Each variable consists of several indicators; the CA variable consists of three indicators, $\mathrm{AV}$ has three indicators, $\mathrm{AF}$ has three indicators, $\mathrm{AC}$ has five indicators, Q has four indicators, and PU has four indicators. The description of each indicator can be seen in Table 1 .

Performance measurement uses an interval scale of 1-10 from very unsuitable (score 1) to very appropriate (score 10). The assessment is carried out by three experts who have the competence and experience of practitioners in ASS in the power tool industry. Calculation of the score of each performance variable $\left(S_{\mathrm{x}}\right)$ on each indicator (i) calculated using the equation (2).

$$
\begin{aligned}
& S_{x}=\sum\left(\left(P_{i}\right)_{j} * w_{j}\right) \\
& \Sigma w_{j}=1 ; \mathrm{i}>0 ; \mathrm{j}>0
\end{aligned}
$$

Where $S_{\mathrm{x}}$ : score of each performance variable (x); $\mathrm{x}: 1, \ldots, 6\left(\mathrm{CA}, \mathrm{AV}, \mathrm{AF}, \mathrm{AC}, \mathrm{Q}\right.$, and PU); $P_{i}$ : the value given by the expert for each $\operatorname{ASS}(i)$ for indicators $j$ use scale 1-10; $i$ : ASS(i), where $\mathrm{i}=$ $1,2,3, \ldots, 12 ; w_{j}:$ weight of each indicator $j$; and $j$ : indicators on each variable $(x)$, where $j=(1,2,3, \ldots$, n).

So, the ASS performance score is the total score of each variable (Sx) obtained, as shown in the formula (3):

$$
\text { Skor } A S S=\sum\left(S_{x}\right)
$$

The service strategy offered by the company at least offers a percentage of six service categories: customer service (97\%), after-sales service (86\%), R \& D-oriented service (86\%), maintenance service $(73 \%)$, operational service (67\%), and smart services (55\%) [27]. The target of achieving ASS performance in this study, for the percentage of aggregate performance grouping based on performance achievement, is grouped into four categories, namely very good $(75 \%<$ score $<100 \%)$, good $(70 \%<$ score $<75 \%)$, poor $(60 \%<$ score $<70 \%)$, and very poor (score $<60 \%)$.

Variables and performance indicators that did not reach the specified minimum targets were analyzed for causes using FGD involving three experts and using FTA tools. The experts involved represent the competence of ASS engineers, ASS managers, and product managers. FTA is used to describe the structure of the causal relationship of the factors that cause performance not to be achieved, and the results obtained as recommendations for improving performance.

Performance measurement uses an interval scale of 1-10 from very unsuitable (score 1) to very appropriate (score 10). The assessment is carried out by three experts who have the competence and experience of practitioners in ASS in the power tool industry. Calculation of the score of each performance variable $\left(S_{\mathrm{x}}\right)$ on each indicator (i) calculated using the equation (2).

$$
\begin{aligned}
& S_{x}=\sum\left(\left(P_{i}\right)_{j} * w_{j}\right) \\
& \Sigma w_{j}=1 ; \mathrm{i}>0 ; \mathrm{j}>0
\end{aligned}
$$

Where $S_{\mathrm{x}}$ : score of each performance variable (x); $S_{\mathrm{x}}: 1, \ldots, 6\left(\mathrm{CA}, \mathrm{AV}, \mathrm{AF}, \mathrm{AC}, \mathrm{Q}\right.$, and PU); $P_{i}$ : the value given by the expert for each $\operatorname{ASS}(i)$ for indicators $j$ use scale 1-10; $i$ : ASS(i), where $\mathrm{i}=$ $1,2,3, \ldots, 12 ; w_{j}:$ weight of each indicator $j$; and $j$ : indicators on each variable $(x)$, where $j=(1,2,3, \ldots$, n).

So, the ASS performance score is the total score of each variable $\left(\mathrm{S}_{\mathrm{x}}\right)$ obtained, as shown in the formula (3):

$$
\text { Skor } A S S=\sum\left(S_{x}\right)
$$

The service strategy offered by the company at least offers a percentage of six service categories: customer service (97\%), after-sales service $(86 \%), \mathrm{R} \& \mathrm{D}$-oriented service $(86 \%)$, maintenance service $(73 \%)$, operational service (67\%), and smart services (55\%) [27]. The target of achieving ASS performance in this study, for the percentage of aggregate performance grouping based on performance achievement, is grouped into four categories, namely very good $(75 \%<$ score $<100 \%)$, good $(70 \%<$ score $<75 \%)$, poor $(60 \%<$ score $<70 \%)$, and very poor (score $<60 \%)$.

Variables and performance indicators that did not reach the specified minimum targets were analyzed for causes using FGD involving three experts and using FTA tools. The experts involved represent the competence of ASS engineers, ASS managers, and product managers. FTA is used to describe the structure of the causal relationship of the factors that cause performance not to be achieved, and the results obtained as recommendations for improving performance 


\section{RESULTS AND DISCUSSION}

\subsection{Results}

The aggregate results of measuring performance achievement from a total of 12 ASS partners for power tools in the areas of Jakarta, Depok, Bandung, Tasikmalaya, Bogor, Cilegon, Sukabumi, Cikarang, and Karawang (Fig. 1). Three partners $(25 \%)$ were able to achieve the minimum performance target, the remaining nine partners $(75 \%)$ have not been able to achieve the target. Three partners whose achievements were able to achieve the minimum set targets, namely ASS (A) with $85 \%$ achievement, ASS (B) with $77 \%$ achievement, and ASS (C) with 76\% achievement.

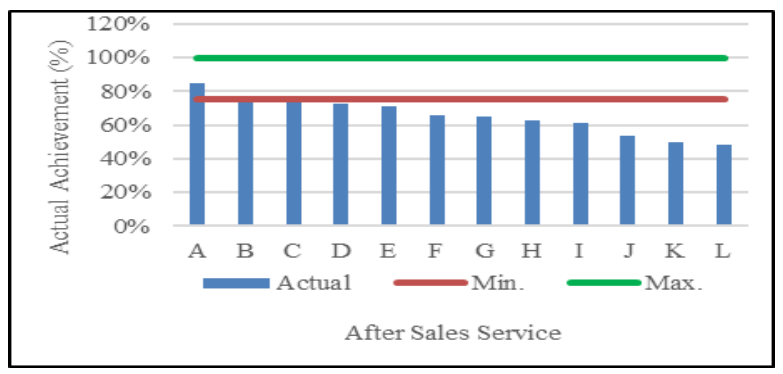

Fig. 1. Performance achievement results

The performance of ASS partners who achieve the minimum target is classified into two categories, $1^{\text {st }}$ ASS, namely ASS (A) is the SC category, $2^{\text {nd }}$ ASS is ASS (B), and ASS (C) is included in the SD2 category, namely SD which has customers from industrial segmentation and serves transactions by online. The performance condition of ASS which can achieve the minimum target, is superior in terms of quality, accuracy, and speed of service. This result is in line with previous research, which found that service dealer partners with the best performance have serviceoriented quality, technical performance, and scheduling.

The performance achievement of each ASS that is evaluated, results of the category of performance achievement are presented in Table 2 . The achievement of the performance target is the sum of the total percentages of the six performance variables, where the result is the highest minimum achievement on the PU variable $(17 \%)$, followed by successive variables. AC (15\%), AV and Q (12\%), AF (11\%), and CA (9\%). There are three partners with good category performance achievements due to the total percentage of six variables. The first result is $85 \%$, the second $77 \%$ and the third $76 \%$, where the three partners are included in the ASS category SC and SD1. Meanwhile, three partners have very poor performance with the first achievement of $40 \%$, the second $50 \%$, and the third $54 \%$, where the three partners are included in the SD2 ASS category.

Table 2. Achievement category results

\begin{tabular}{cccc}
\hline $\begin{array}{c}\text { After Sales } \\
\text { Service }\end{array}$ & $\begin{array}{c}\text { Achievement } \\
(\%)\end{array}$ & $\begin{array}{c}\text { ASS } \\
\text { category }\end{array}$ & $\begin{array}{c}\text { Achievement } \\
\text { status }\end{array}$ \\
\hline A & $85 \%$ & SC & Good \\
B & $77 \%$ & SD2 & Good \\
C & $76 \%$ & SD2 & Good \\
D & $73 \%$ & SD1 & Bad \\
E & $71 \%$ & SD1 & Bad \\
F & $66 \%$ & SD1 & Bad \\
G & $65 \%$ & SD1 & Bad \\
H & $63 \%$ & SD1 & Bad \\
I & $61 \%$ & SD1 & Bad \\
J & $54 \%$ & SD1 & Very Bad \\
K & $50 \%$ & SD1 & Very Bad \\
L & $48 \%$ & SD1 & Very Bad \\
\hline
\end{tabular}

Table 3. Performance achievement (SC vs SD1 vs SD2)

\begin{tabular}{cll}
\hline Variable & Indicator & \\
\hline CA & CA1 & SC \& SD2 better than SD1 \\
& CA2 & SC \& SD2 better than SD1 \\
& CA3 & SC \& SD2 better than SD1 \\
AV & AV1 & SC \& SD2 better than SD1 \\
& AV2 & SC = SD1 = SD2 \\
& AV3 & SC \& SD2 better than SD1 \\
AF & AF1 & SC = SD1 = SD2 \\
& AF2 & SC \& SD2 better than SD1 \\
& AF3 & SC \& SD2 better than SD1 \\
AC & AC1 & SC = SD1 = SD2 \\
& AC2 & SC = SD1 = SD2 \\
& AC3 & SC = SD1 = SD2 \\
& AC4 & SC \& SD2 better than SD1 \\
& AC5 & SC \& SD2 better than SD1 \\
Q & Q1 & SC \& SD2 better than SD1 \\
& Q2 & SC \& SD2 better than SD1 \\
& Q3 & SC \& SD2 better than SD1 \\
& Q4 & SC \& SD2 better than SD1 \\
PU & P1 & SC \& SD2 better than SD1 \\
& P2 & SC \& SD2 better than SD1 \\
& P3 & SC \& SD2 better than SD1 \\
& P4 & SC = SD1 = SD2 \\
\hline
\end{tabular}



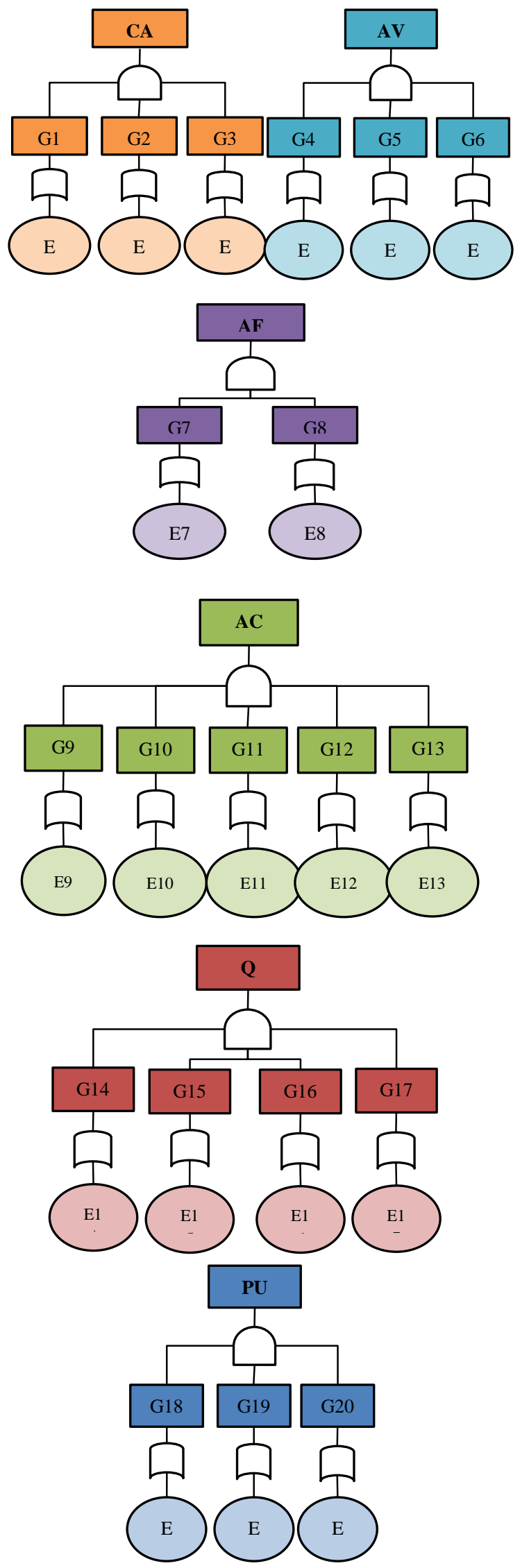

Fig. 2. FTA performance constraint
The ability of ASS performance to achieve the target in six performance variables with the following results: on $\mathrm{CA}$ and $\mathrm{Q}$ variables (8 partners), $\mathrm{AV}$ and $\mathrm{AF}$ variables (5 partners), $\mathrm{PU}$ variables (3 partners), and $\mathrm{AC}$ variables (1 partner). AC variable shows poor performance achievement in almost all partners, and only one partner can achieve the target.

Furthermore, the details of the achievement of scores for each indicator on the performance variable are carried out. The performance of all partners on the two performance indicators (AF1 and $\mathrm{P} 1$ ) reached the minimum target; on the contrary, the performance of all partners on the two performance indicators (AV2 and P1) did not reach the minimum target. The performance capabilities of all ASS partners on performance indicators, then a comparison is made on each performance indicator, what category of ASS is better, this data can be seen in Table 3 .

From the analysis of 22 ASS performance indicators in the power tool industry, 20 performance indicators have not been able to reach the minimum target. The factors causing the obstacles to not achieving performance on the 20 indicators using the FTA method are diagrammatically presented in Fig. 2 .

Logic gate items constrain performance achievement in the power tool industry are denoted by the initial letter $\mathrm{G}$ and basic events with the initial letter $\mathrm{E}$. The descriptions of each logic gate and basic event are summarized in Table 4 and Table 5. Based on the results of the FGD, 20 indicators that cause obstacles to achievement were determined. ASS performance of the six performance variables on ASS operations.

\subsection{Discussion}

In the CA variable, there are three indicators related to the construction and ASS indicators [2], where the indicators are (1) the identity of ASS related to the convenience and trust of customers on after-sales service, (2) serving many brands related to the consistency of the service provided if it is not provided separately by technicians, (3) training related to increasing the competence of technicians so that they are speedy and accurate in carrying out technical services. In the AV variable, there are three indicators related to customer satisfaction and are included in the mandatory category for ASS [10], where these indicators are the availability and control of spare 
Table 4. Indicators of the causes of performance constraints (Logic Gate)

\begin{tabular}{clc}
\hline No & \multicolumn{1}{c}{ Logic gate } & Code \\
\hline 1 & Service consistency is not good & G1 \\
2 & Brand image is not good & G2 \\
3 & Technical competence in service & G3 \\
4 & Part availability is not good & G4 \\
5 & Part availability data is not updated & G5 \\
6 & Safety stock availability is not running & G6 \\
7 & The reported number of paid repairs data is not the same as performance measurement data & G7 \\
8 & Data on the number of paid repairs there are cases of cancellation, due to price & G8 \\
9 & The unit entry upgrade for repairs doesn't improve well & G9 \\
10 & There is no unit entry as a result of the pick-up service & G10 \\
11 & Customers have a pause when contacting service & G11 \\
12 & Customer convenience is less comfortable & G12 \\
13 & Customers must come to the location for transactions & G13 \\
14 & Service accuracy and speed & G14 \\
15 & There are cases of presales claims submitted by the warranty process & G15 \\
16 & Used parts under warranty are not stored according to procedures & G16 \\
17 & The warranty process is not by the procedure & G17 \\
18 & Data tools that are completed in 24 hours are not real-time & G18 \\
19 & Repaired warranty tools data does not match performance measurement data & G19 \\
20 & Do regularly collect input from users & G20 \\
\hline
\end{tabular}

Table 5. Indicators of the causes of performance constraints (Basic Event)

\begin{tabular}{clc}
\hline No & \multicolumn{1}{c}{ Basic event } & Code \\
\hline 1 & Serving many brands & E1 \\
2 & No sign board identity & E2 \\
3 & Not attending regular training & E3 \\
4 & Not well controlled & E4 \\
5 & Not reported & E5 \\
6 & No stock management system & E6 \\
7 & Data does not match what was reported & E7 \\
8 & Pricing policy is not implemented properly & E8 \\
9 & Does not provide pick-up service & E9 \\
10 & There is no good increase in the number of unit entries & E10 \\
11 & Does not have a service center number & E11 \\
12 & Road access is less crowded, customer parking space is inadequate & E12 \\
13 & The sales distribution network is not online & E13 \\
14 & Complete work tools are not available & E14 \\
15 & Not following procedures from the center & E15 \\
16 & The warranty process is not by the procedure & E16 \\
17 & Used parts under warranty are not stored according to procedures & E17 \\
18 & Activity reports are reported at the beginning of the month H+3 & E18 \\
19 & Data does not match what was reported & E19 \\
20 & Does not have a system for input from users & E20 \\
\hline
\end{tabular}

Information:

\begin{tabular}{clll}
\multicolumn{2}{l}{ Information: } & & \\
\hline Color & Variable & Problem & Root Cause \\
\hline & CA & & \\
& AV & & \\
& AF & & \\
& AC & & \\
Q & & \\
PU & & \\
\hline
\end{tabular}


parts, namely whether the stock is well controlled, availability is reported regularly. Periodically to the center, and has a stock management system. These indicators relate to the accuracy and speed of the services provided. If not executed properly, it can result in waiting times due to the unavailability of spare parts, which impact customer dissatisfaction with the services provided.

Indicators on the AF variable relate to service affordability, a very reliable relationship with customer satisfaction with ASS [24], the indicators relate to pricing policies and ASS procedures. This indicator needs to be controlled systemically to find out whether the price policy regulated for services and spare parts is carried out properly by after-sales service partners. This can lead to customer dissatisfaction if the standardization of prices for services and spare parts is not uniform.

The indicators on the $\mathrm{AC}$ variable are related to the accuracy and speed of service access provided by the very reliable ASS and are related to customer satisfaction [24]. The indicators are no special hotline for the convenience of customers to contact the service center, interservice facilities, pick-up for service accessibility which has an impact on increasing incoming units. As well as establishing maintenance and repair cooperation for customers with industrial segments or business entities, online transactions can increase the distribution of goods more broadly because the limited distance perceived by customers can be anticipated with online transactions.

The indicator in the $\mathrm{Q}$ variable relates to operational procedures that need to be controlled, controlled, and monitored properly because there are discrepancies such as the spare parts price policy related to performance measurement and profitability management, in this case, the mechanism that rationalizes the costs of activities and processes and measures performance results [25]. The indicators included in the $Q$ variable are warranty spare parts are not stored according to the rules, warranty procedures are applied to products with presales claim status, noncompliance with regulations can have a bad impact on brand image in providing after-sales service systems to customers.

The indicators on the PU variable are related to skills, speed of service, which are summarized in the service activity report data [24], but the problem with the data obtained is not real-time because it is reported manually via email every month every $\mathrm{H}+3$ at the beginning of the month. This condition can be simulated by providing a good report, so it is necessary to build a system in ASS whose data can be retrieved and viewed in real-time so that its accuracy can be known, and the correct speed of service under expected conditions.

Based on the results of the evaluation of the performance of ASS partners in the power tool industry, it was found that the performance of the service center was still not as expected where performance indicators such as brand loyalty, brand equity, training, spare parts controlling, spare parts stock management, affordability of services in terms of price, service center number, pick-up service, online transaction system, warranty procedure, service activity reporting system, user input system.

\section{CONCLUSION}

The actual condition of the performance of ASS partners in the power tools industry in this study is still not satisfactory because only $25 \%$ of partners can achieve the minimum target of a total of 12 partners evaluated. Partners in the service center (SC) achieved good performance and service dealer 2 (SD2) categories who have customers from the industrial and e-commerce segments. The results of the achievement of performance can affect the brand image of the company or brand.

The factors causing the non-achievement of performance related to several performance indicators such as brand loyalty \& equity, human factors namely training, method factors namely user input systems, spare parts control \& stock management, price affordability, central service, pick-up services, online transaction systems, warranty procedures, service activity reporting system. The contributing factor is mainly due to the operating system that is run conventionally, not cooperative from partners in participating in human resource development programs for technicians and admin officers.

\section{REFERENCES}

[1] S. Shahrouzifard and M. Faraji, "Aftersales service quality as an antecedent of customer satisfaction," Accounting, 2016. Available:

http://m.growingscience.com/beta/ac/219 5-after-sales-service-quality-as-an- 
antecedent-of-customer-satisfaction.html.

[2]

C. V. V. Miriam Borchardt, Marcelo

Souza, Giancarlo M. Pereira, "Achieving better revenue and customers' satisfaction with after-sales services: how do the best branded car dealerships get it?," Int. J. Qual. Reliab. Manag., 2017. doi: 10.1108/IJQRM-01-2017-0016.

[3] H. W. Lightfoot and H. Gebauer, "Exploring the alignment between service strategy and service innovation," J. Serv. Manag., vol. 22, no. 5, pp. 664-683, Jan. 2011, doi: 10.1108/09564231111175004.

[4] N. Saccani, L. Songini, and P. Gaiardelli, "The role and performance measurement of after-sales in the durable consumer goods industries: An empirical study," Int. J. Product. Perform. Manag., vol. 55, no. 3-4, pp. 259-283, 2006, doi: 10.1108/17410400610653228.

[5] S. Rezapour, J. K. Allen, and F. Mistree, "Reliable product-service supply chains for repairable products," Transp. Res. Part $E$, vol. 95, pp. 299-321, 2016, doi: 10.1016/j.tre.2016.07.016.

[6] S. A. Brax, A. Calabrese, N. Levialdi Ghiron, L. Tiburzi, and C. Grönroos, "Explaining the servitization paradox: a configurational theory and a performance measurement framework," Int. J. Oper. Prod. Manag., 2021, doi: 10.1108/IJOPM08-2020-0535.

[7] G. Pagalday, P. Zubizarreta, J. Uribetxebarria, A. Erguido, and E. Castellano, "Efficient development and management of after sale services," Procedia Manuf., vol. 19, no. 2017, pp. 18-25, 2018, doi: 10.1016/j.promfg.2018.01.004.

[8] G. Tavakoli, M. Feyz Arefi, O. Heidari, and M. Mirjafari, "Designing conceptual model of after-sales services, in companies producing the capital goods, with the idea of value co-creation," Int. J. Qual. Serv. Sci., vol. 8, no. 2, pp. 122-142, 2016, doi: 10.1108/IJQSS-07-2015-0055.

[9] U. Dombrowski and C. Malorny, "Service Planning as Support Process for a Lean after Sales Service," Procedia CIRP, vol. 64, pp. 324-329, 2017, doi: 10.1016/j.procir.2017.03.080.
[10] S. Shokouhyar, S. Shokoohyar, and S. Safari, "Research on the influence of aftersales service quality factors on customer satisfaction," J. Retail. Consum. Serv., vol. 56, no. May, p. 102139, 2020, doi: 10.1016/j.jretconser.2020.102139.

[11] F. Pakdil, "Total Quality Management \& Business Excellence A quality function deployment application using qualitative and quantitative analysis in after sales services," no. September 2014, pp. 37-41, 2012 ,

doi: 10.1080/14783363.2012.715797.

[12] S. Weigel and K. Hadwich, "Success factors of service networks in the context of servitization - Development and veri fi cation of an impact model," Ind. Mark. Manag., no. June, pp. 0-1, 2018, doi: 10.1016/j.indmarman.2018.06.002.

[13] J. L. Cummings and S. R. Holmberg, "Best-fit Alliance Partners: The Use of Critical Success Factors in a Comprehensive Partner Selection Process," Long Range Plann., vol. 45, no. 2-3, pp. 136-159, 2012, doi: 10.1016/j.lrp.2012.01.001.

[14] S. Murali, S. Pugazhendhi, and C. Muralidharan, "Evaluation of performance of after sales service - a comparative study involving home appliances manufacturing firms," ARPN J. Eng. Appl. Sci., vol. 10, no. 13, pp. 5614-5619, 2015. Available: http://arpnjournals.com/jeas/research_pap ers/rp_2015/jeas_0715_2300.pdf

[15] V. Sillanpää, "Performance measurement in welfare services: A survey of Finnish organisations," Meas. Bus. Excell., vol. 15, no. 4, pp. 62-70, 2011, doi: 10.1108/13683041111184116.

[16] E. Syahrial, H. Suzuki, and S. J. Schvaneveldt, "The impact of serviceability-oriented dimensions on after-sales service cost and customer satisfaction," Total Qual. Manag. Bus. Excell., vol. 30, no. 11-12, pp. 1257-1281, 2019 , doi: 10.1080/14783363.2017.1365595.

[17] R. F. Saen and S. Nia, "Evaluating aftersales service units by developing inverse network data envelopment analysis model," Benchmarking An Int. J., 2019, doi: 10.1108/BIJ-01-2019-0017. 
[18] D. Battaglia, M. Borchardt, M. A. Sellitto, and G. M. Pereira, "Service recovery: A method for assessing performance," Bus. Process Manag. J., vol. 18, no. 6, pp. 949 963, 2012, doi: $10.1108 / 14637151211283366$.

[19] H. C. Choi, W. Lee, H. Sung, and C.-F. Chiu, "Evaluation of the Service Performance: Application of the Zone of Tolerance with Importance Performance Analysis of a Convention Facility," in Tourists' Behaviors and Evaluations, vol. 9, Emerald Group Publishing Limited, 2014, pp. 9-19. doi: 10.1108/S1871317320140000009000.

[20] S. Çevik Onar, B. Oztaysi, and C. Kahraman, "Dynamic intuitionistic fuzzy multi-attribute aftersales performance evaluation," Complex Intell. Syst., vol. 3, no. 3, pp. 197-204, 2017, doi: 10.1007/s40747-017-0047-7.

[21] P. Y. Hsu, M. Aurisicchio, P. Angeloudis, and J. Whyte, "Understanding and visualizing schedule deviations in construction projects using fault tree analysis," Eng. Constr. Archit. Manag., vol. 27, no. 9, pp. 2501-2522, 2020, doi: 10.1108/ECAM-01-2020-0058.

[22] M. Marzouk and E. Mohamed, "Modeling bid/no bid decisions using fuzzy fault tree," Constr. Innov., vol. 18, no. 1, pp. 90108, 2018, doi: 10.1108/CI-11-2016-0060.
[23] S. Ahmad and M. Mohsin Butt, "Can after sale service generate brand equity?," Mark. Intell. Plan., vol. 30, no. 3, pp. 307-323, Jan. 2012, doi: 10.1108/02634501211226285.

[24] S. Murali, S. Pugazhendhi, and C. Muralidharan, "Assessment of impact of after sales service attributes on customer satisfaction for a home-appliances manufacturing firm," Int. J. Enterp. Netw. Manag., vol. 7, no. 1, pp. 27-41, Jan. 2016, doi: 10.1504/IJENM.2016.075172.

[25] A. Pistoni and L. Songini, "Strategic managerial control for the servitization strategy," Stud. Manag. Financ. Account., vol. 32, pp. 111-224, 2017, doi: 10.1108/S1479-351220170000032003.

[26] F. S. Ahmad, A. Ihtiyar, and R. Omar, "A Comparative Study on Service Quality in the Grocery Retailing: Evidence from Malaysia and Turkey," Procedia - Soc. Behav. Sci., vol. 109, pp. 763-767, 2014, doi: 10.1016/j.sbspro.2013.12.541.

[27] J. Hsuan, T. Frandsen, and J. Raja, "Survey of the Danish Servitization Landscape: Service Performance and Service Strategies," pp. 1-19, 2018. Available: https://blog.cbs.dk/servitization/wpcontent/uploads/2018/11/20181108Survey_WEB.pdf. 